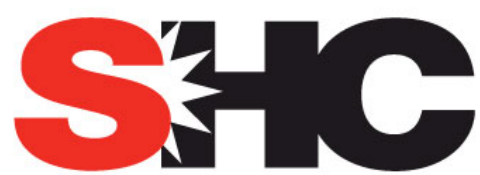

SOLAR HEATING \& COOLING PROGRAMME INTERNATIONAL ENERGY AGENCY
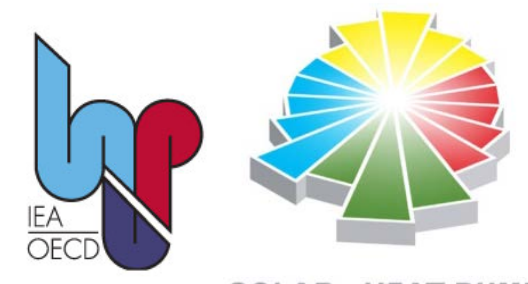

SOLAR + HEAT PUMP

\title{
A Review of Market-Available Solar Thermal Heat Pump Systems
}

A technical report of subtask $A$

Date: 18.03 .2013

By Jörn Ruschenburg and Sebastian Herkel ${ }^{1}$ with contributions from W. Becke, M. D'Antoni, S. Eicher, K. Ellehauge, H. Focke, M. Haller, M. Huber, I. Katić, A. Loose, I. Malenković, A. Thür and M. Vukits

${ }^{1}$ Institution

Address

Phone

Fax

e-mail
Fraunhofer ISE

Heidenhofstr. 2, 79110 Freiburg, Germany

+4976145885117

+49761 45889117

sebastian.herkel@ise.fraunhofer.de 


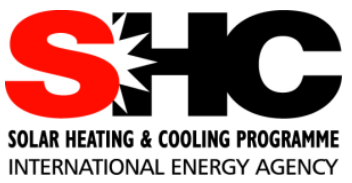

\section{IEA Solar Heating and Cooling Programme}

The International Energy Agency (IEA) is an autonomous body within the framework of the Organization for Economic Co-operation and Development (OECD) based in Paris. Established in 1974 after the first "oil shock," the IEA is committed to carrying out a comprehensive program of energy cooperation among its members and the Commission of the European Communities.

The IEA provides a legal framework, through IEA Implementing Agreements such as the Solar Heating and Cooling Agreement, for international collaboration in energy technology research and development (R\&D) and deployment. This IEA experience has proved that such collaboration contributes significantly to faster technological progress, while reducing costs; to eliminating technological risks and duplication of efforts; and to creating numerous other benefits, such as swifter expansion of the knowledge base and easier harmonization of standards.

The Solar Heating and Cooling Programme was one of the first IEA Implementing Agreements to be established. Since 1977, its members have been collaborating to advance active solar and passive solar and their application in buildings and other areas, such as agriculture and industry. Current members are:

$\begin{array}{lll}\text { Australia } & \text { Finland } & \text { Singapore } \\ \text { Austria } & \text { France } & \text { South Africa } \\ \text { Belgium } & \text { Italy } & \text { Spain } \\ \text { Canada } & \text { Mexico } & \text { Sweden } \\ \text { Denmark } & \text { Netherlands } & \text { Switzerland } \\ \text { European Commission } & \text { Norway } & \text { United States } \\ \text { Germany } & \text { Portugal } & \end{array}$

A total of 49 Tasks have been initiated, 35 of which have been completed. Each Task is managed by an Operating Agent from one of the participating countries. Overall control of the program rests with an Executive Committee comprised of one representative from each contracting party to the Implementing Agreement. In addition to the Task work, a number of special activitiesMemorandum of Understanding with solar thermal trade organizations, statistics collection and analysis, conferences and workshops—-have been undertaken.

Visit the Solar Heating and Cooling Programme website - www.iea-shc.org - to find more publications and to learn about the SHC Programme. 
Current Tasks \& Working Group:

Task 36

Task 39

Task 40

Task 41

Task 42

Task 43

Task 44

Task 45

Task 46

Task 47

Task 48

Task 49
Solar Resource Knowledge Management

Polymeric Materials for Solar Thermal Applications

Towards Net Zero Energy Solar Buildings

Solar Energy and Architecture

Compact Thermal Energy Storage

Solar Rating and Certification Procedures

Solar and Heat Pump Systems

Large Systems: Solar Heating/Cooling Systems, Seasonal Storages, Heat Pumps

Solar Resource Assessment and Forecasting

Renovation of Non-Residential Buildings Towards Sustainable Standards

Quality Assurance and Support Measures for Solar Cooling

Solar Process Heat for Production and Advanced Applications

Completed Tasks:

Task 1

Task 2

Task 3

Task 4

Task 5

Task 6

Task 7

Task 8

Task 9

Task 10

Task 11

Task 12

Task 13

Task 14

Task 16

Task 17

Task 18

Task 19

Task 20

Task 21

Task 22

Task 23

Task 24

Task 25

Task 26

Task 27

Task 28

Task 29

Task 31

Task 32

Task 33

Task 34

Task 35

Task 37

Task 38
Investigation of the Performance of Solar Heating and Cooling Systems

Coordination of Solar Heating and Cooling R\&D

Performance Testing of Solar Collectors

Development of an Insolation Handbook and Instrument Package

Use of Existing Meteorological Information for Solar Energy Application

Performance of Solar Systems Using Evacuated Collectors

Central Solar Heating Plants with Seasonal Storage

Passive and Hybrid Solar Low Energy Buildings

Solar Radiation and Pyranometry Studies

Solar Materials R\&D

Passive and Hybrid Solar Commercial Buildings

Building Energy Analysis and Design Tools for Solar Applications

Advanced Solar Low Energy Buildings

Advanced Active Solar Energy Systems

Photovoltaics in Buildings

Measuring and Modeling Spectral Radiation

Advanced Glazing and Associated Materials for Solar and Building Applications

Solar Air Systems

Solar Energy in Building Renovation

Daylight in Buildings

Building Energy Analysis Tools

Optimization of Solar Energy Use in Large Buildings

Solar Procurement

Solar Assisted Air Conditioning of Buildings

Solar Combisystems

Performance of Solar Facade Components

Solar Sustainable Housing

Solar Crop Drying

Daylighting Buildings in the 21st Century

Advanced Storage Concepts for Solar and Low Energy Buildings

Solar Heat for Industrial Processes

Testing and Validation of Building Energy Simulation Tools

PV/Thermal Solar Systems

Advanced Housing Renovation with Solar \& Conservation

Solar Thermal Cooling and Air Conditioning

Completed Working Groups:

CSHPSS; ISOLDE; Materials in Solar Thermal Collectors; Evaluation of Task 13 Houses; Daylight Research 


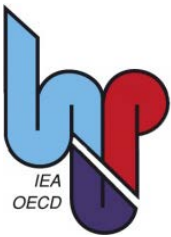

\section{IEA Heat Pump Programme}

This project was carried out within the Solar Heating and Cooling Programme and also within the Heat Pump Programme, HPP which is an Implementing agreement within the International Energy Agency, IEA. This project is called Task 44 in the Solar Heating and Cooling Programme and Annex 38 in the Heat pump Programme.

The Implementing Agreement for a Programme of Research, Development, Demonstration and Promotion of Heat Pumping Technologies (IA) forms the legal basis for the IEA Heat Pump Programme. Signatories of the IA are either governments or organizations designated by their respective governments to conduct programmes in the field of energy conservation.

Under the IA collaborative tasks or "Annexes" in the field of heat pumps are undertaken. These tasks are conducted on a cost-sharing and/or task-sharing basis by the participating countries. An Annex is in general coordinated by one country which acts as the Operating Agent (manager). Annexes have specific topics and work plans and operate for a specified period, usually several years. The objectives vary from information exchange to the development and implementation of technology. This report presents the results of one Annex. The Programme is governed by an Executive Committee, which monitors existing projects and identifies new areas where collaborative effort may be beneficial.

\section{The IEA Heat Pump Centre}

A central role within the IEA Heat Pump Programme is played by the IEA Heat Pump Centre (HPC). Consistent with the overall objective of the IA the HPC seeks to advance and disseminate knowledge about heat pumps, and promote their use wherever appropriate. Activities of the HPC include the production of a quarterly newsletter and the webpage, the organization of workshops, an inquiry service and a promotion programme. The HPC also publishes selected results from other Annexes, and this publication is one result of this activity.

For further information about the IEA Heat Pump Programme and for inquiries on heat pump issues in general contact the IEA Heat Pump Centre at the following address:

\section{IEA Heat Pump Centre}

Box 857

SE-501 15 BORÅS

Sweden

Phone: +4610165512

Fax: +46 33131979

Visit the Heat Pump Programme website - http://www.heatpumpcentre.org/ - to find more publications and to learn about the HPP Programme.

\footnotetext{
Legal Notice Neither the IEA Heat Pump Centre nor the SHC Programme nor any person acting on their behalf: (a) makes any warranty or representation, express or implied, with respect to the information contained in this report; or (b) assumes liabilities with respect to the use of, or damages, resulting from the use of this information. Reference herein to any specific commercial product, process, or service by trade name, trademark, manufacturer, or otherwise, does not necessarily constitute or imply its endorsement recommendation or favouring. The views and opinions of authors expressed herein do not necessarily state or reflect those of the IEA Programmes, or any of its employees. The information herein is presented in the authors' own words.
} 


\section{Contents}

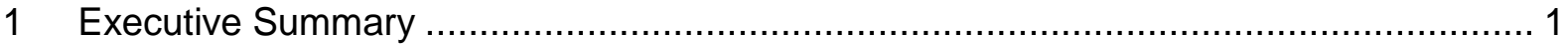

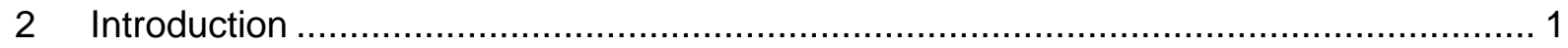

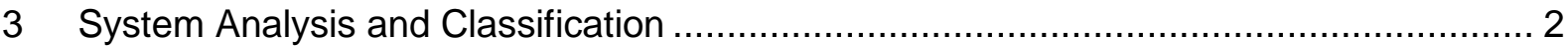

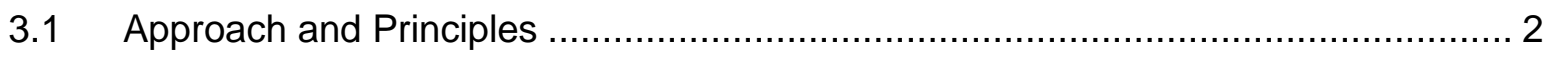

3.2 Systematic Graphical Representation of Solar Heat Pumps................................... 2

3.3 Denotation Scheme.................................................................................. 5

3.4 Simplified Notation and Classification............................................................ 5

4 Comparative Analysis of Market-Available Systems .............................................. 6

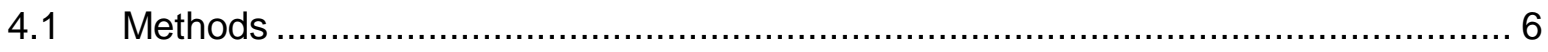

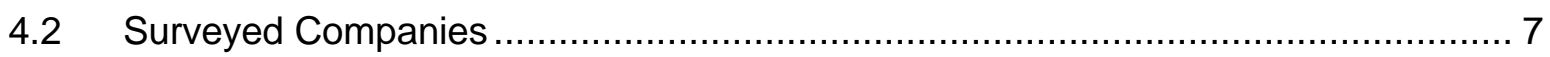

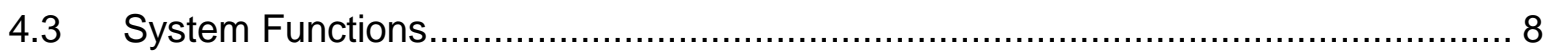

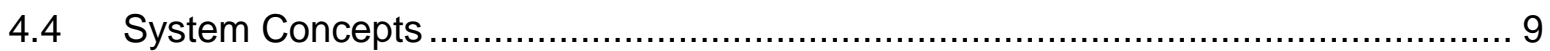

4.5 Heat Pump Characteristics - Energy Sources …..............................................10

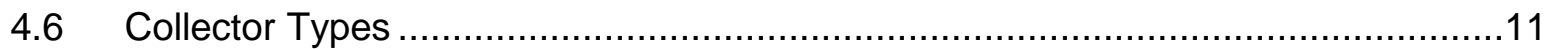

4.7 Cross Analysis between Collector Type and System Concept ..........................11

5 Relevance and market penetration - illustrated with the example of Germany .............12

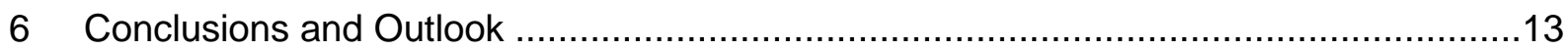

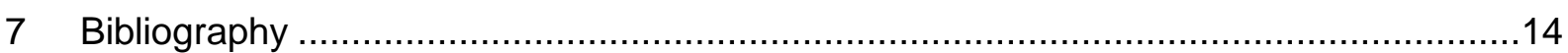

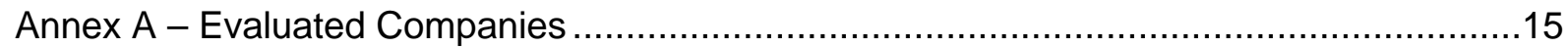




\section{Executive Summary}

Solar heat pump systems seen as a combination of a solar thermal collector and a compression heat pump already entered the market with more than 130 systems offered. The aim of this report is to collect, to describe and to analyse these currently available systems.

There are five main criteria to describe a solar heat pump system: (i) The use of the generated heat; (ii) the low temperature source(s) for the heat pump; (iii) the energy carrier used to drive the system; (iv) the function and placement of storages in the system and (v) the interactions between these components. For the latter, abstract descriptions like parallel, serial or regenerative are used as well as its combinations. In addition the systems will be described by the type of used components like flat-plate, unglazed or evacuated tube collectors. Furthermore, the efficiency of such a system depends on the ratio of sizing of the components and the control. Thus, a simple qualitative classification of these systems with the aim of an easy communication to the public leads not to a satisfying solution. Nevertheless the systems can be categorized by such criteria, depending on the leading question to be answered.

A unified graphical representation is presented which reflects qualitative criteria mentioned above, called "square view". The systematic description of the systems is completed by a non-ambiguous denotation scheme and a categorisation scheme.

The undertaken survey shows that most of the systems are used for a combined production of domestic hot water and heat for the space heating circuit. In addition, many systems are able to deliver cold as well. Approximately a quarter uses ambient air as only source for the heat pump, a quarter the ground and nearly half of the systems are multisource or other systems. Seven combinations of serial, parallel and regenerative layouts can be found on the today's market. As additional result of the market survey, the need for flexible performance figures and testing methods becomes visible. It was, for example, shown that serial or more complex configurations are widely distributed, which is ignored by today's standards. In these cases, solar energy is extensively used as energy source for the heat pump, though not directly as useful energy. Consequently, assessment methods are required taking into account the energy both consumed from and fed-in to the grid, similar to cogeneration systems.

\section{Introduction}

Numerous combinations of heat pumps and solar thermal collectors, henceforward referred to as solar heat pump (SHP) systems, became market-ready during the last years. It is evident, as shown in Section 4.2, that some systems entered the market even in the early 1980s, obviously motivated by the second oil crisis. An explicit and enduring trend developed just in the current century, though. This storyline shows much similarity to that of the nonsolar heat pump market in Europe (cf. Nowak and Murphy 2011).

The idea of combing solar energy with heat pumps has already been reflected decades ago and is revived in younger publications by means of theoretical analysis, simulation studies, laboratory tests or field tests. However, there is a lack of methods or even standards for the assessment of such systems. With regard to the specific system concepts and boundary conditions, it has to be investigated whether a significant enhancement of the solar gain as 
well as a reduced primary energy demand of the heat supply system can be achieved compared to a "conventional" solution.

\section{System Analysis and Classification}

\subsection{Approach and Principles}

The fact that, in literature, various specifications are analysed to describe or compare SHP systems is clearly demonstrated by Frank et al. 2010. Depending on the respective interests, independent authors focus on parameters that seldom coincide. The aspects chosen for the scope of this report are listed in Table 1. Additionally, it can be seen to which extent these parameters were surveyed and/or analysed by other authors.

Table 1: Examined parameters and their prevalence

\begin{tabular}{|c|c|c|c|c|c|}
\hline Parameters & 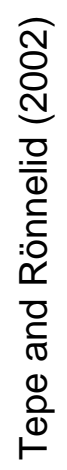 & 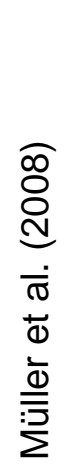 & 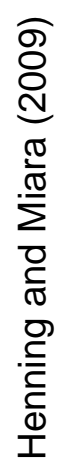 & 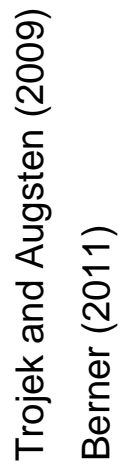 & 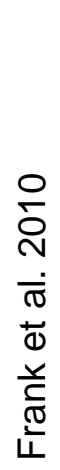 \\
\hline provenance and distribution & & & & $x$ & \\
\hline system functions & $x$ & $x$ & & $x$ & $x$ \\
\hline system concept & $x$ & $x$ & $x$ & & $x$ \\
\hline heat pump characteristics & & $x$ & $x$ & $x$ & $x$ \\
\hline collector characteristics & & $x$ & & & $x$ \\
\hline
\end{tabular}

The possibilities to set up categories for a system classification are equally various. For example, the systems can be described by the type of applied components like flat-plate, unglazed or evacuated tube collectors, or alternatively by the refrigerant used in the heat pump cycle. Furthermore, the efficiency of such a system is dependent on the location, on the sizing of the components and on the control. So, a simple classification of these systems with the aim of an easy communication to the public leads not to a satisfying solution.

In this chapter, a graphical representation is introduced to systematically analyse and to compare solar heat pump systems. Afterwards, these examinations result in the derivation and presentation of a denotation scheme and a classification approach.

\subsection{Systematic Graphical Representation of Solar Heat Pumps}

Basically, the visualisation presented in this report is similar to energy flow charts that are frequently used in building energy engineering. Instead of a whole building, it is the heating system that is illustrated centrally against white background, including energy-storing (blue 
objects) and energy-transforming components (orange objects). The analysis of many combined solar and heat pumps systems resulted in the finding of five recurring components. They comprise collector, heat pump and backup heater, complemented by storages, namely one on the source side and one on the sink side of the heat pump. For these components, fixed positions are defined. Still, specifications like the collector type may be chosen. As defined boundaries (grey background), environmental energy (green objects) enters the system from above, final or "to be purchased" energy - in case of electricity generating systems even "bidirectional traded" energy - from the left (dark grey objects). Useful energy like DHW flows to the right (red objects).

In any case, the information provided by the colouring is an additional feature, i.e. it is not essential for understanding the presented concept. In theory, any losses would be shown leaving the system downwards. However, because of the purely qualitative nature of the analytical approach, component sizes, efficiencies, etc. are not shown, and thus no losses. A label for the manufacturer's and the concept's name is added in the lower left part.

The final step is the depiction of energy flows connecting certain components. In doing so, the figure is enhanced to become a qualitative energy flow chart. Each line style refers to the carrier medium, except the driving energies that are mostly without mass, e.g. solar irradiation. A simple example for a complete visualisation is given by Figure 1.

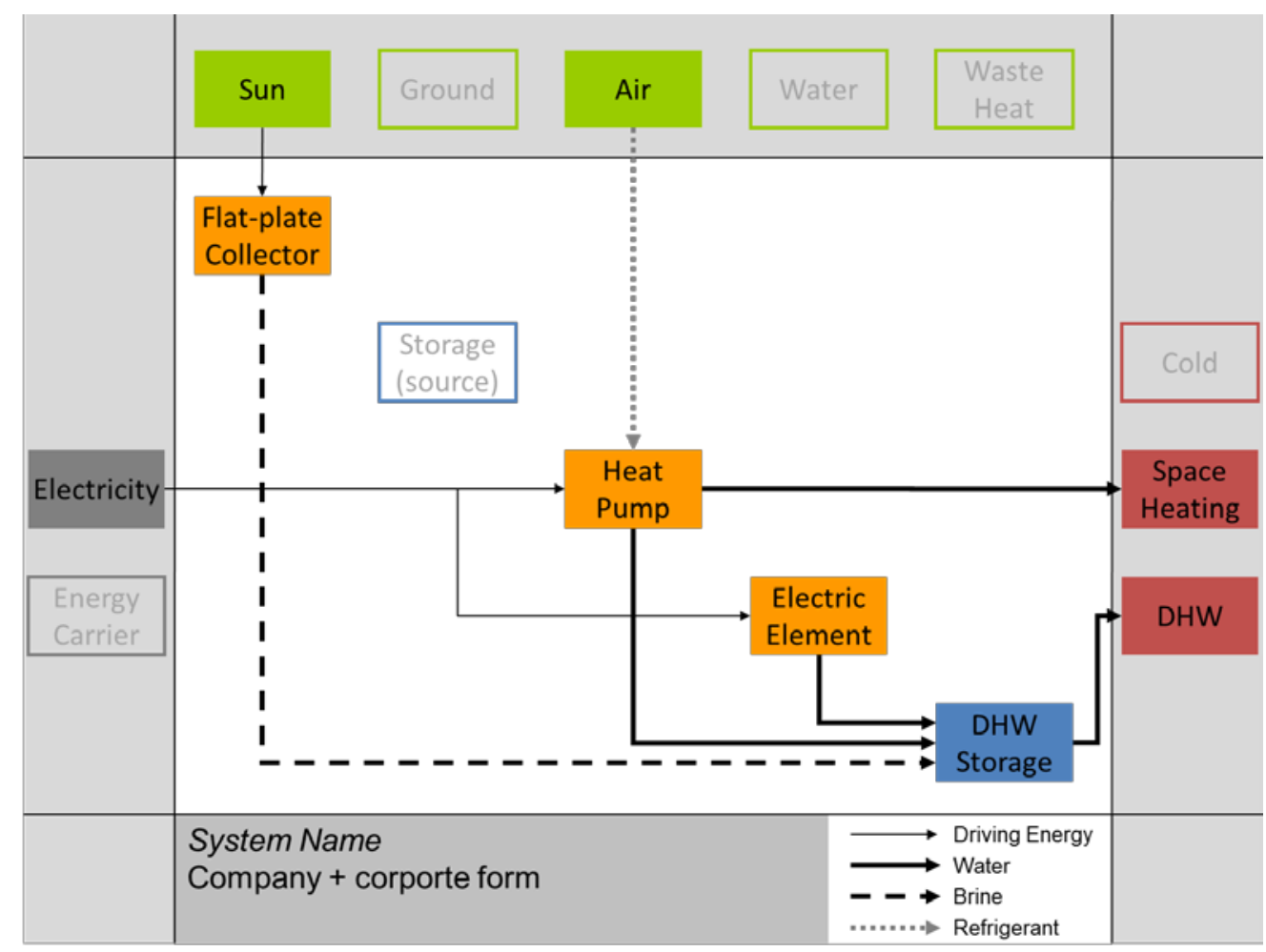

Figure 1: Introductory example for the visualisation scheme

It has to be pointed out that all possible operational modes of one system (excluding defrosting) are shown simultaneously in one visualisation. All components appearing in a particular system are depicted as filled, other components remain as shaded frame as placeholders for orientation and comparability purposes. 

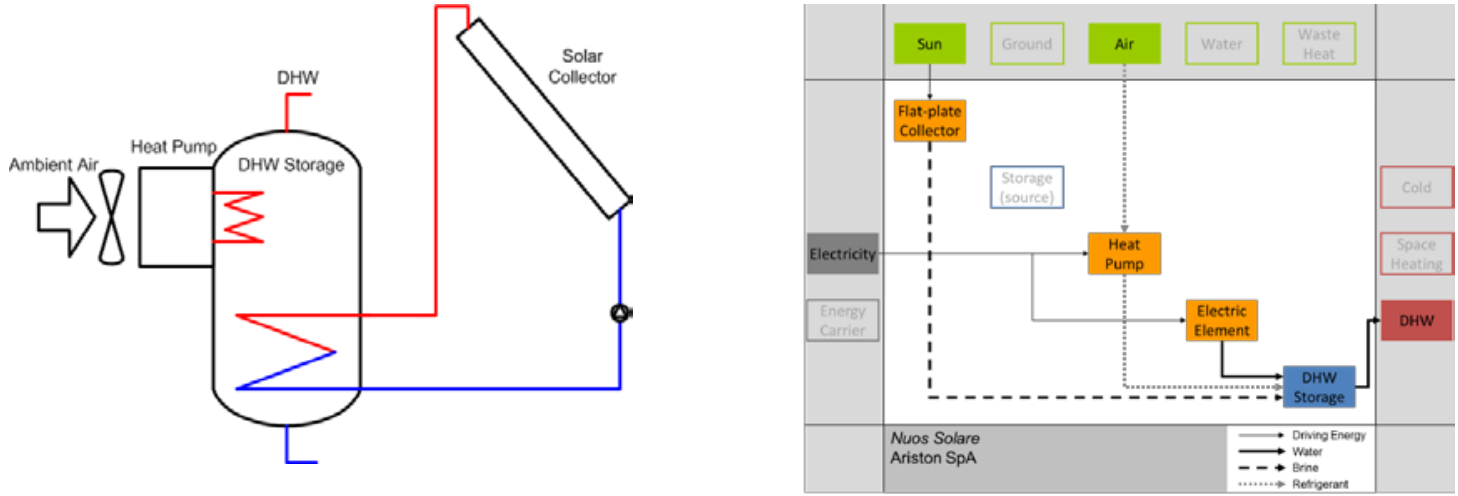

Figure 2: Simplified hydraulic scheme (left) and visualisation (right) of a solar heat pump system "Nuos Solare" by Ariston Thermo SpA. The system is exclusively designed for the heating of DHW. It features a flat-plate collector and a direct-evaporating air source heat pump with its condenser immersed in a DHW storage.
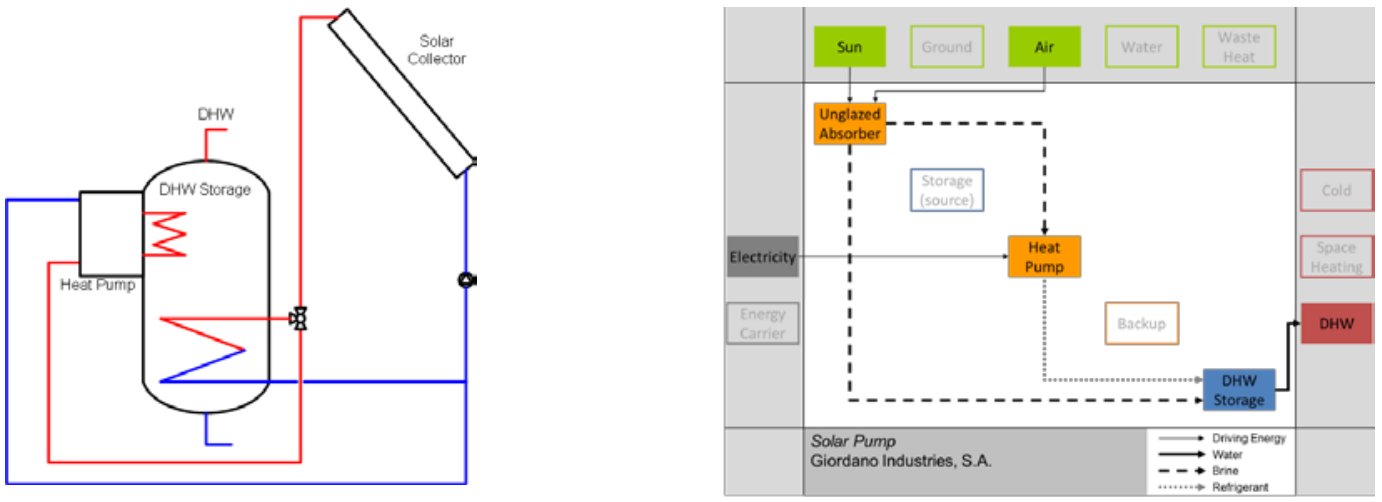

Figure 3: Simplified hydraulic scheme (left) and visualisation (right) of a solar heat pump system "Solar Pump" by Giordano Industries, S.A.. The system is exclusively designed for the heating of DHW. It features an unglazed collector and a heat pump with its condenser immersed in a DHW storage.
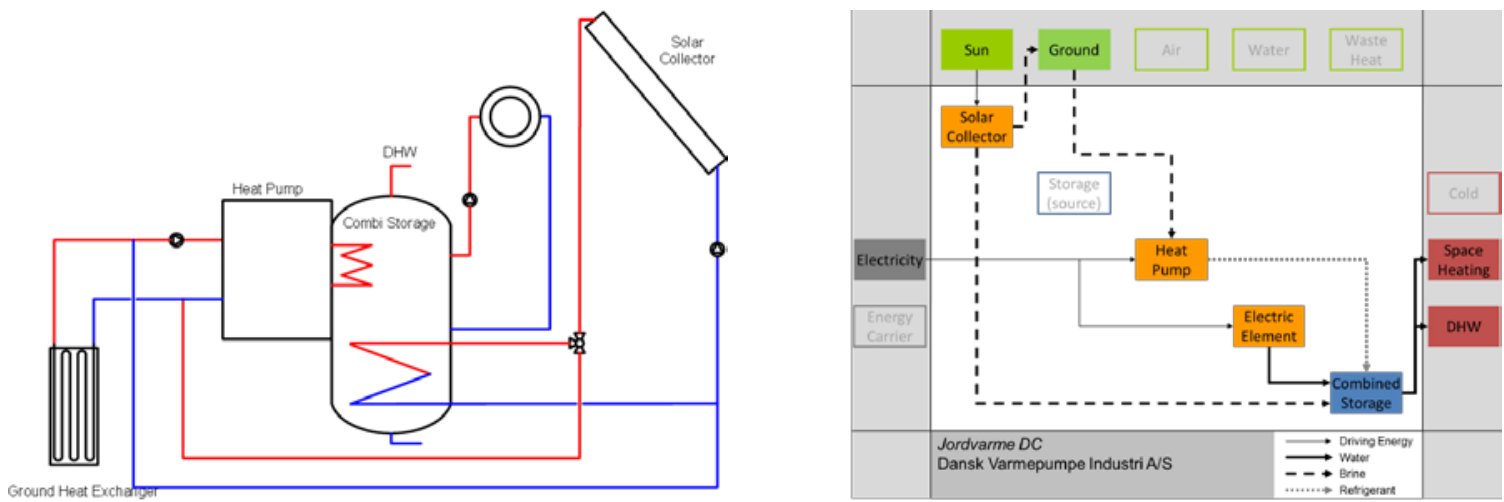

Figure 4: Simplified hydraulic scheme (left) and visualisation (right) of a solar heat pump system "Jordvarme DC" by Dansk Varmepumpe Industri A/S. The system is designed for DHW preparation as well as space heating (symbol of two concentric circles). It features an unspecified collector and a heat pump with its condenser immersed in a combined storage tank.

In the figures above, the presented visualisation scheme is applied to typical system concepts. Here, a hydraulic scheme is used as well, considerably simplifying any hydraulics and ignoring the application of backup heating elements. The comparison between the figures gives an impression of the visualisation method's capability. As an additional finding, 
it can be seen that the arrangement defined above results in energy flows mostly in left-toright and up-down directions, though of course, the variety of combinations results in exceptions.

\subsection{Denotation Scheme}

With the exception of backup heating, the information comprised in the visualisation schemes in Section 3.2 can also be denoted in letters with the abbreviation code shown in Table 2 and the convention that the sources and sinks of the solar collector (S) and the heat pump (HP) are indicated with superscripts (sources) and subscripts (sinks) around the abbreviation SHP which stands for solar heat pump:

\section{$\underset{\text { sinks }}{\text { sources }} S H P_{\text {sinks }}^{\text {sources }}$}

Table 2: Abbreviations used for transferring the system information into a letter code

\begin{tabular}{|ll|ll|ll|}
\hline S & solar collector & Air & air & srS & source-side storage \\
\hline HP & heat pump & G & ground & skS & sink-side storage \\
\hline Sol & solar irradiation & W & ground water & SH & space heating (directly) \\
\hline
\end{tabular}

With this way of notation, the systems shown in Section 3.2 would be denoted as follows:

"Nuos Solare" by Ariston Thermo SpA

"Solar Pump" by Giordano Industries, S.A.

"Jordvarme DC" by Dansk Varmepumpe Industri A/S
Figure 2

Figure 3

Figure 4

\section{${ }_{\text {sks }}^{\text {Sol }}{ }_{\text {skS }}^{\text {Air }}$} Sol,Air
skS,HP

${ }^{\text {Sol }}$ SHP ${ }^{G}$ sks ${ }_{\text {skS }}$

Such a formalised notification scheme allows a further use as base for simplified performance calculations for solar heat pump systems.

\subsection{Simplified Notation and Classification}

For the scope of this report, the system concepts are defined by the way the heat pump and the solar subsystem interact. Typically (cf. Freeman et al. 1979, Citherlet et al. 2008), the following distinction is made:

- Collector and heat pump independently supply useful energy (space heating and/or DHW), usually via one or more storages. This configuration is denoted as "parallel".

- The collector acts as a source of the heat pump, either as exclusive or as additional source, and either directly or via a buffer storage. This configuration is denoted as "serial".

A third concept shall be used here, namely the use of solar energy to "regenerate" the actual source of the heat pump, usually ground, which is comprehensively described and examined 
by Kjellson (2009). The regenerative approach could possibly be regarded as a subset of the serial concept. There are conceptual and operational differences, though: Regenerative operation is usually applied to improve or at least to maintain the quality of the ground source for long time scales or merely to prevent solar collector stagnation (cf. Hartmann and Schwarzburger 2009). Consequently, regenerative operation usually occurs in summer, when highest solar availability and lowest heating demand concur, i.e., when the heat pump is off. Many systems were found on the market indeed featuring a regenerative mode explicitly, partially without an intended serial mode. The objection that the regenerative concept is presented neither by Freeman et al. nor by Citherlet et al. can obviously be explained by the fact that only non-regenerable air-source heat pump systems were examined then.

Nevertheless, it was realised within these publications that concepts can be combined within one system, or in other words, that parallel and serial arrangements do not exclude each other. The counting of all possible combinations of the three proposed options - while ignoring permutations, redundancies and the trivial case of "none" - results therefore in 7 concepts. Cooling functions of SHP systems are not represented by this approach, though they might provide regenerative effects as well.

If we use $P$ (parallel), $S$ (serial or source) and $R$ (regeneration) as abbreviations for the options, and if we put the abbreviation SHP for "Solar Heat Pump" in front to indicate the subject of classification and to add recognition value, we get categories like:

- $\quad$ SHP/P (cf. Figure 2)

- SHP/P,S (cf. Figure 3)

- $\quad$ SHP/P,R (cf. Figure 4)

- etc.

\section{Comparative Analysis of Market-Available Systems}

The basis of the presented analyses is formed by 135 combined solar thermal heat pump systems, provided by 88 companies from 11 countries.

\subsection{Methods}

The presented and analysed systems were surveyed between October 2011 and September 2012 by members of 10 research institutions participating in Task 44 / Annex 38 (see title page). This means that companies were preferably searched and contacted by native speakers being at the same time proven experts in the field of modern heating technology. Like all activities of Task 44 / Annex 38, the market survey and the subsequent analyses are limited to SHP systems that are equipped with electrical-driven heat pumps and designed for DHW preparation and/or residential space heating. Cooling functions are documented as supplementary information only.

In principle, any heat pump can be combined with any solar thermal collector. Therefore, only those companies were taken account of which genuinely provide at least one of the main components, i.e. solar collector, heat pump, storage(s) and/or controller. Research projects are also ignored; gigantic numbers of individual SHP systems would accumulate otherwise.

To ensure comparability, the characteristics of each SHP system were documented in a harmonised way on two-sided fact sheets, including data on the overall concept, hydraulics, 
dimensioning and system control, as well as technical specifications mainly of the collector, heat pump and storage(s). Most data are derived from online or print sources, though personal contact to representatives of the companies could be established in most of the cases, enabling interviews. Anyhow, it is clear that the correctness of the retrieved information cannot be checked systematically and independently. Moreover, completeness cannot be claimed. The fact that the majority of identified companies originates from countries $^{1}$ officially participating in Task 44 / Annex 38 might possibly be explained by the barrier of language, resulting in certain countries erroneously being underrepresented or even unrepresented.

It has to be noted that in the following analyses, all systems are treated equally, i.e., without respecting the number of installations. Respecting the number of installations for each system would certainly lead to quite different results. The data base is incomplete here, but when it comes to market penetration, most conventional approaches - as can be expected outnumber the less classical configurations. Finally, it is pointed out that, due to imperfect data collection, the sample size is not necessarily constant throughout this paper. From the 88 researched companies, for example, all appear in Figure 5 but only 60 in Figure 6 . But as all figures are labelled with absolute numbers, the sample size can easily be calculated if desired.

The aspects to be analysed were already presented in Table 1. Certain surveyed aspects will not be examined here. The reason is that their application turned out to be most flexible, and thus hardly comparable, comprising:

- additional heat generators, i.e. back-up components like electric heating elements, gasfuelled boilers or wood stoves; sometimes offered optionally and almost always diversified regarding type, number and way of integration,

- $\quad$ storage characteristics, e.g. number and function; separated storages for space heating and DHW can be chosen for most systems as well as combined storages, and

- the dimensioning of any components, e.g. nominal heating capacity, collector area and storage volume; these are too flexible to be specified for comparative analyses.

It is clear that many companies offer more than one system. So, in conjunction with the discussion on parameters to be analysed, the question arises which parameters are defined as being distinctive. Within the scope of the survey, either a different concept (cf. Section 4.4) or a different source of the heat pump (cf. Section 4.5) justifies a "distinguishable" system. It has to be accepted that this decision is to some extent arbitrary. Depending on the reader, the collector type or the refrigerant used within the heat pump might be regarded as more important, and a consideration of these aspects would unquestionably result in a multiple of "distinguishable" systems.

\subsection{Surveyed Companies}

As it can be seen in Figure 5, most of the surveyed companies are based in Germany (48\%) or Austria (19\%). Only a minority of all companies, however, restricts their market to one or two countries. The strong majority distributes their systems in three or more specified countries, even beyond those already named below, e.g. to Croatia or to Greece. Being available "in Europe" or "worldwide" was claimed less frequently.

\footnotetext{
${ }^{1}$ confer Figure 5; all presented countries except of Sweden and China officially participate in Task 44 / Annex 38
} 


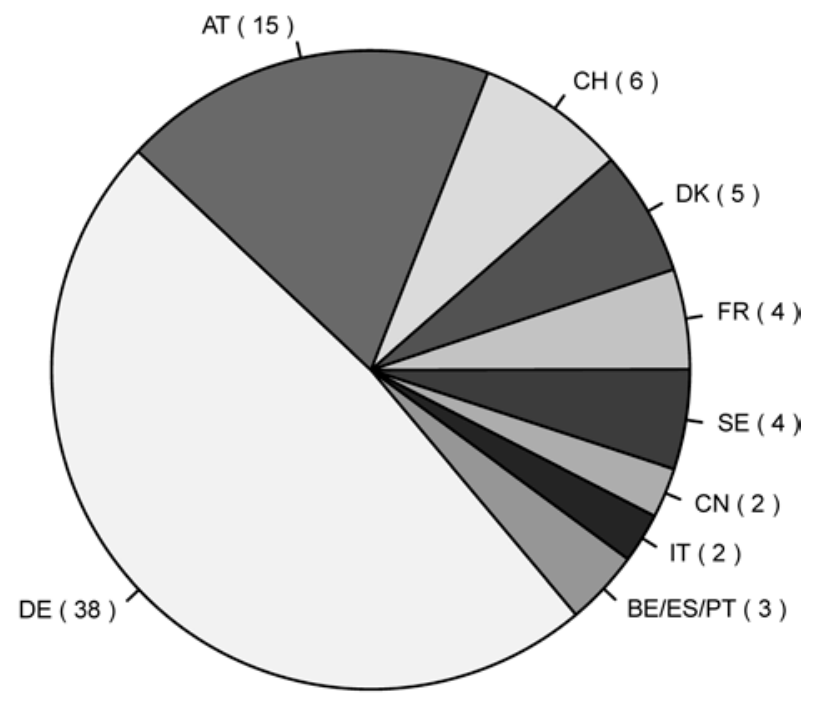

Figure 5: Surveyed companies by country

Figure 6 shows that most companies entered the SHP market in recent years. It has to be noted that systems withdrawn from the market before or during the time the survey was conducted are ignored. Few are known to the authors, and it is estimated that their complete number is rather small.

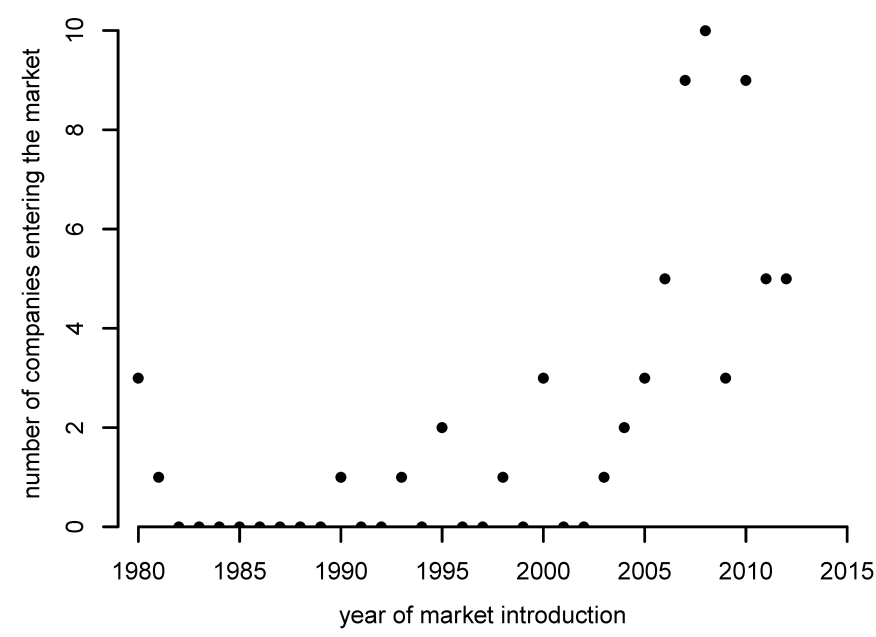

Figure 6: Companies entering the market of solar heat pump systems (The oldest system offered by each company is used as indicator, provided that it is still marketed today.)

\subsection{System Functions}

The main functions for SHP systems, especially for residential applications, are space heating and the preparation of DHW. Figure 7 shows that both of these functions are featured in most cases. In contrast, few market-available systems are exclusively designed for DHW preparation. The fact that all Chinese systems and significant shares of the systems originating from the Mediterranean countries (France, Italy, Spain) are included within the latter is identified as strong indicator for market-specific and climate-specific system layout. Regarding the technical design, these "DHW only" systems can be divided into two groups: Roof-top thermosyphon constructions backed-up by an (air-source) heat 
pump appear to be representative for China. In Europe, in contrast, storage and (often exhaust-air) heat pumps are typically installed indoors as one integrated unit, with the condenser of the heat pump immersed in the storage tank or coiled around it.

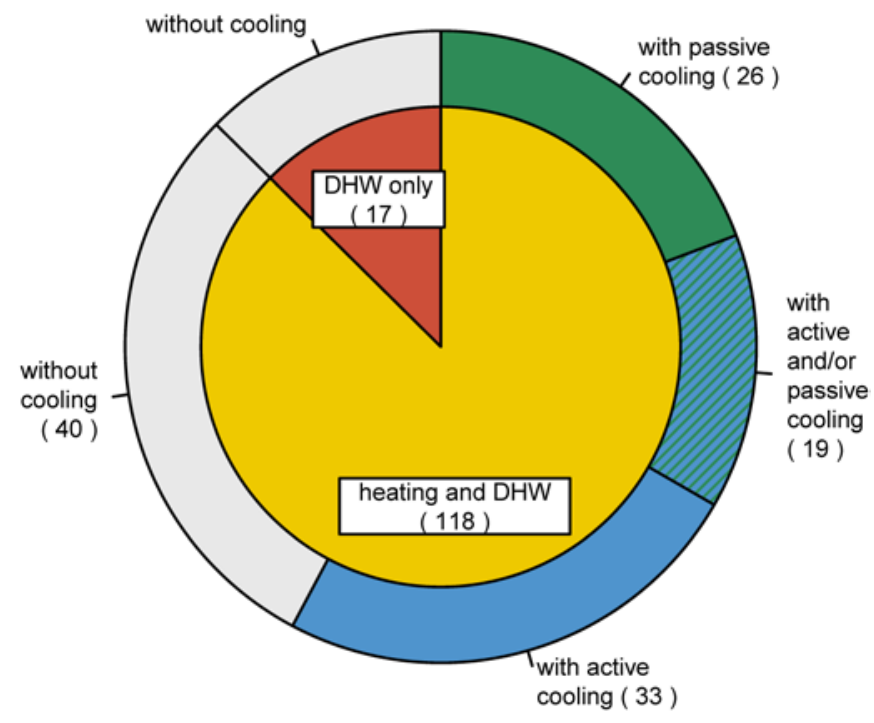

Figure 7: Surveyed systems by function

Space cooling functions were surveyed supplementary. Interestingly, more than half of the systems (58\%) are capable of "active" cooling via heat pump operation and/or "passive" cooling via ground or water source, also known as "free" or "natural" cooling. As it is seen in Figure 7, this applies only to systems that already offer space heating.

It appears that air/air heat pumps, as popular as they might be for residential cooling and sometimes also heating purposes, are not combined with solar thermal systems. Instead, hydronic distribution is applied without exception. Here, floor-heating systems are repeatedly recommended though rarely defined as mandatory.

As to the DHW preparation, modern hygienic approaches are found to be popular, given by internal heat exchangers (20\% of the systems), e.g. corrugated pipes, by external fresh water stations (24\%) or by either solution to be selected (additional $7 \%$ ). Austrian companies offer such technologies much above average.

\subsection{System Concepts}

The classification approach introduced in Section 3.4, applied to the surveyed systems, results in a fragmentation that is shown by Figure 8.

The "parallel only" concept, which is simpler in design, installation and control, clearly dominates (61\%). SHP systems with "serial only" (6\%) or "regenerative only" concepts $(1 \%)$ are rare. Most impressively, concepts with any combination of parallel, serial and/or parallel modes amount to no less than $33 \%$. 


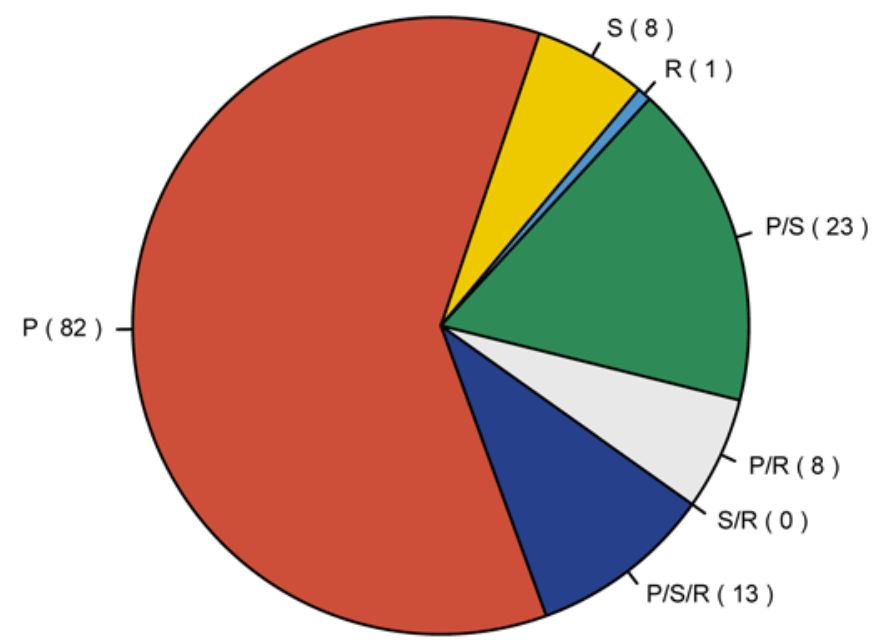

Figure 8: Surveyed systems by concept

\subsection{Heat Pump Characteristics - Energy Sources}

Leaving aside air/air heat pumps mainly used for space cooling in Mediterranean countries, it can be said that ambient air and ground are the most common sources for heat pump installations in Europe, while water and exhaust air cover smaller shares (cf. Nowak and Murphy 2011). Though not recorded by such statistics, Figure 8 demonstrates that energy converted by solar collectors is repeatedly utilised as a source, i.e. the serial concept and its variations. It becomes clear that even the "serial-only" concept allows other possible sources within the same system.

Regarding the classical sources, Figure 9 illustrates that either pure air-source or pure ground-source heat pumps together are applied in half of the surveyed systems, namely 27 $\%$ and $23 \%$, respectively. Water (9\%) or exhaust air (2\%) are utilised as a source in few systems. Commercial SHP systems with waste-water or other sources appear untraceable.

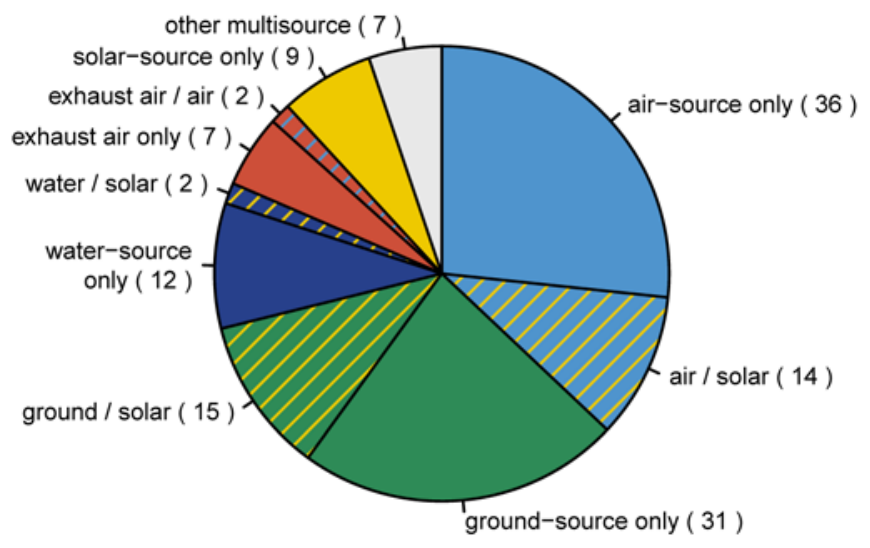

Figure 9: Surveyed systems by source

Systems using solar energy as the sole source amount to $7 \%$. For a further $23 \%$, solar energy is used in addition to other conventional sources (air, ground or water). Such multisource systems require technical solutions which can be split into two groups, external and internal ones. The former refers to modified hydraulics between solar subsystem and heat 
pump, e.g. by heat exchangers between solar loop and ground-source loop or even by joint brine loops. Thus, conventional heat pumps and solar collectors can be used. The latter means that either the heat pump or the solar collectors are specifically designed to be integrated within serial SHP systems. Though this approach is rare, offered by not more than 6 companies, it comprises the most alternative solutions, including:

- multi-source evaporators (two evaporators within one refrigerant cycle),

- directly-evaporating solar collectors (with refrigerant as circulating fluid for the solar loop), and

- hybrid collectors (the solar thermal collectors includes also the ambient air unit with integrated fan or other "active" technology).

\subsection{Collector Types}

Within the conducted survey, the collector type was chosen as the most significant parameter to compare the applied solar subsystem. The results are shown in Figure 10. Questions on additional characteristics - e.g. regarding the circulating fluid, material, operational modes, Solar Keymark certification or handling of stagnation - were answered incomprehensively, and thus, these parameters cannot be presented in comparative form.

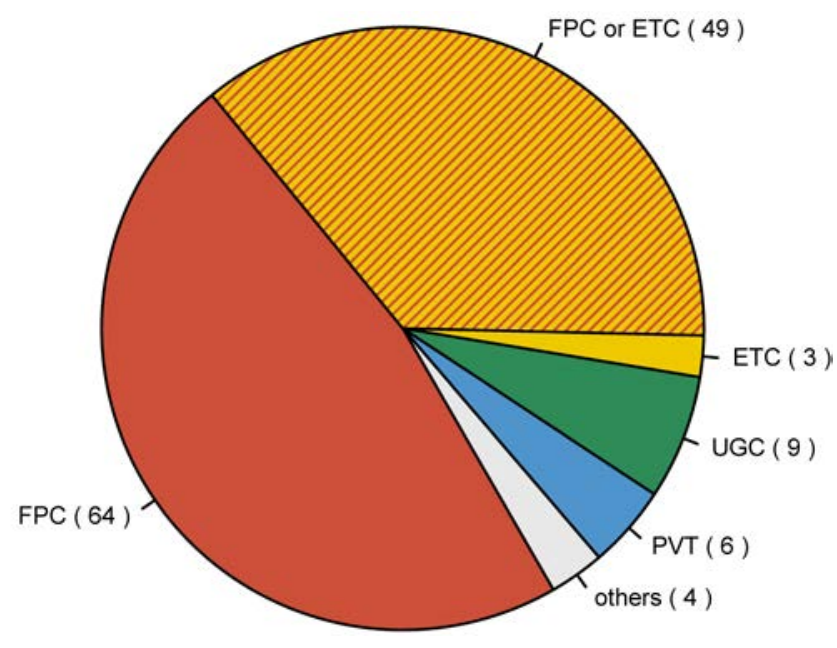

Figure 10: Surveyed systems by collector type

Flat-plate collectors (FPC) are stipulated in nearly half of the systems (47\%), whereas evacuated tube collectors (ETC) are essential only in the fewest cases (2\%). Instead, the choice between these two types is frequently left open, i.e. affected by the conditions on-site as well as the preferences of client and installer (36\%). Uncovered or unglazed collectors (UGC) are found repeatedly (7\%), mainly in specific applications (cf. Section 4.7). Recently developed photovoltaic-thermal (PVT) collectors are found only in few market-available SHP systems (4\%), according to this survey for the first time in 2011.

\subsection{Cross Analysis between Collector Type and System Concept}

When compared to flat-plate and evacuated tube collectors, photovoltaic-thermal and unglazed collectors are efficient only at low temperatures and thus inefficient for space heating and even more for the preparation of DHW. Independently, from the basics of heat pump technology, it is known that the source temperature for residential heating applications is relatively low - though at the same time desired to be as high as possible, given the 
conditions at site. The logical reasoning out of these observations would be that, if installed within SHP systems, UGCs and PVT collectors are preferably applied to concepts with serial and/or regenerative character while FPCs and ETCs are favoured for parallel concepts.

The acquired data (cf. Figure 8 and Figure 10) allows verification by means of correlation. Figure 11 is a bubble plot with discrete values in all dimensions. The labelling for the collector types is given in accordance to Section 4.6, for the system concepts in accordance with Section 3.4. The area of each bubble is proportional to the number of respective systems.

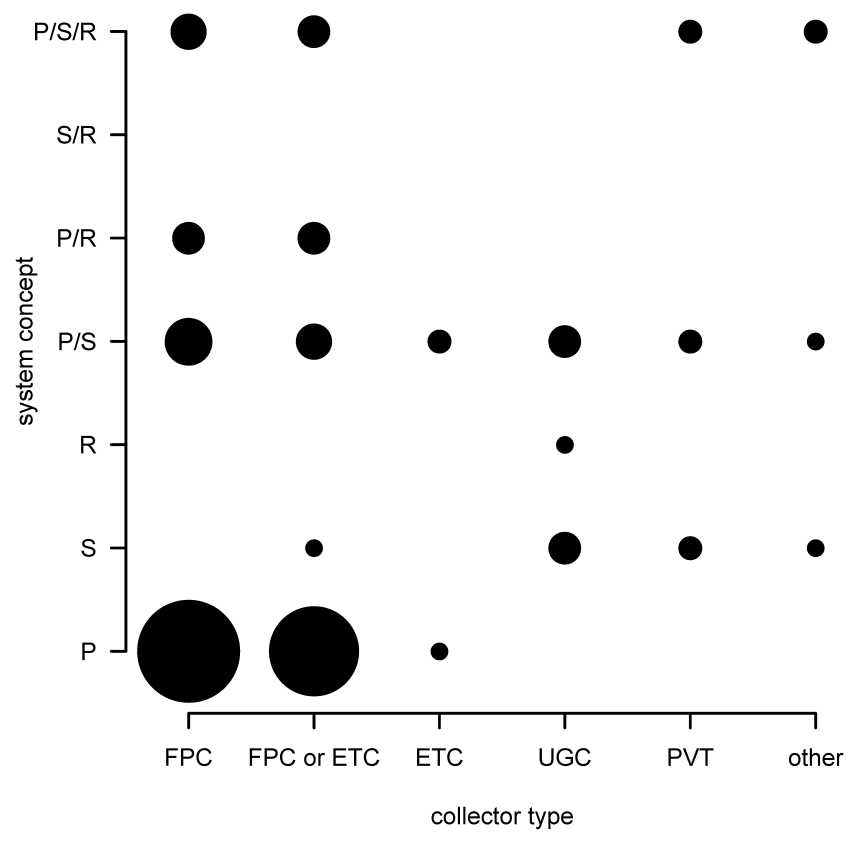

Figure 11: Surveyed systems correlated by collector type and system concept

FPCs and ETCs preponderate within the "parallel-only" concept and all of its combinations. In contrast, UGCs and PVT collectors are never applied to "parallel-only" concepts but dominate both "serial-only" and "regenerative-only" concepts. This last insight is especially interesting, given the fact that FPCs or ETCs are found in $86 \%$ of the systems in total. All in all, it is evident that the marketed systems mirror the theoretical considerations given above.

\section{Relevance and market penetration - illustrated with the example of Germany}

This section deals with the question to which extent SHP penetrated the market, or in other word, how many SHP systems are installed, either in absolute numbers or relative to conventional, i.e. non-solar heat pump systems.

Unfortunately, such numbers are not monitored systematically, either on national or on international level. Separated numbers, without information about possible combinations, are well-established for both heat pumps and solar thermal collectors. For example, the European Solar Thermal Industry Federation ESTIF covers European solar thermal markets in great detail, and its comprehensive statistics are available online. Similarly, the European Heat Pump Association EHPA presents the development of European heat pump markets, 
though for members only. However, neither of these or other institutions deals with combination.

Furthermore, the manufacturers of heating equipment present their numbers carefully. In personal communications to the authors, they typically state that between 5 and $10 \%$ of the produced heat pumps are installed with a solar thermal combination. A company distributing products as separated units instead of system solution is usually not able to provide any numbers. Partly, companies are not willing to state any numbers, which has of course to be accepted.

Nevertheless, some other indicative values can be presented here, only referring to the German market. There are two reasons why Germany is chosen here. First, it is shown Section 4.2 that its market is most considerable compared to any other monitored country. Second, it is the only country where data was available at all, aggregated by three independent institutions. The results are explained in the following:

- The Federal Office of Economics and Export Control (Bundesamt für Wirtschaft und Ausfuhrkontrolle BAFA): Among other activities, this office promotes renewable energies by means of subsidisation. If a heat pump is installed in combination with a solar thermal system, an additional "combination bonus" can be granted, introduced in 2008. Since then, about $11 \%$ of the supported heat pump installations also received the combination bonus (BAFA 2012). It has to be noted that BAFA subsidies are only applicable to renovation projects of certain size, and only upon application. Thus, less than a quarter of the German heat pump or solar thermal market is covered.

- Institut Wohnen und Umwelt (IWU) and Bremer Energie Institut (BEI): These institutes used a method were 7500 questionnaires were answered by building owners or property managers in 2009. After evaluating and scaling-up of these data, it is found that heat pumps are installed in about $1.5 \%$ of about 18 million residential buildings in Germany. SHP systems exist in about $0.4 \%$ of the buildings, or in other words, $26 \%$ of the heat pumps are installed in a solar thermal combination. Information regarding the statistical uncertainties can be found in the report (IWU 2010).

- The Institute for Heating and Oil Technology (Institut für Wärme und Oeltechnik IWO): This institute conducts a yearly survey with about 1000 heating installation companies, asking for the numbers of installations of typical heat generators, and for the combination with solar thermal energy in particular. Both new buildings and renovation projects are covered. According to these surveys between 2008 and 2011, among 20 and $27 \%$ of the electrical-driven heat pumps were combined with solar thermal systems (IWO 2012).

\section{Conclusions and Outlook}

In this report, approaches for the analysis, representation and categorisation of solar heat pump systems were presented. They are based on scientific literature and the analysis of market-available systems. Three complementary elements were elucidated:

- a simplified graphical system representation used as qualitative analysis tool,

- a notation scheme, and

- a categorisation approach.

The last approach with its 7 categories can be applied to all solar heat pump systems known today and also to future systems. Unlike former approaches, its categories do not exclude each other. It is therefore meant to replace former descriptions. 
Within a market survey carried out by participants from several countries, 135 marketavailable SHP systems were identified. Most companies offer "conventional" systems with FPCs in parallel arrangement for both space heating and preparation of DHW. Still, manifold alternatives are found for each analysed parameter.

As a main result of this survey, many technological and market-specific particularities of SHP systems are identified. For example, the fact that all Chinese systems and significant shares of the systems originating from the Mediterranean countries are designed for DHW preparation without space heating is identified as strong indicator for market-specific and climate-specific system layout.

Probably the best example regarding the system design is the extensive usage especially of unglazed collectors in serial concepts. Here, it is evident that the industry follows theoretical considerations both in ecology and economy. This approach is, by definition, infeasible for non-solar heat pumps system as well as for solar heating systems combined with any fossil fuel heating.

As additional result of this survey, the need for flexible performance figures and testing methods becomes visible. It was, for example, shown that serial or more complex configurations are widely distributed in Europe, which is ignored by today's standards. In these cases, solar energy is extensively used as source energy for the heat pump though not directly as useful energy. The application of PVT collectors in market-ready systems is a rather young trend. Consequently, assessment methods are required taking into account the energy both consumed from and fed-in to the grid, similar to cogeneration systems.

Based on these results, performance figures as well as monitoring concepts can be developed to assess existing and even future systems. For example, it may be found that certain concepts are in general less efficient or that increased technical complexity required for some configurations does not result in a corresponding increased performance.

The trend shown in Figure 6 suggests that further companies will enter the market of SHP systems soon. Furthermore, even systems offered today may be subject to changes in system concept or its components. The introduction of PVT collectors and the choice of refrigerants are examples. The dynamic history should remind the readers that the situation as presented in this report is merely a snap-shot.

\section{Bibliography}

BAFA Bundesamt für Wirtschaft und Ausfuhrkontrolle, „Marktanreizprogramm - geförderte Anlagen“, 2012, unpublished

Berner, J., „Wärmepumpe und Solar. Solarenergie den Vortritt lassen“, Sonne Wind \& Wärme 35 (8), 2011, 182-186

Citherlet, S., Bony, J., Nguyen, B., "SOL-PAC: Analyse des performances du couplage d'une pompe à chaleur avec une installation solaire thermique pour la rénovation - Rapport final", Haute Ecole d'Ingénierie et de Gestion du Canton de Vaud (HEIG-VD). Laboratoire d'Energétique Solaire et de Physique du Bâtiment (LESBAT), 2008, Yverdon-les-Bains, Switzerland

Frank, E., Haller, M., Herkel, S., Ruschenburg, J., "Systematic classification of combined solar thermal and heat pump systems", Proc. of the International Conference on Solar Heating, Cooling and Buildings, 2010, Graz, Austria 
Freeman, T L., Mitchell, J W., Audit, T E., "Performance of combined solar-heat pump systems", Solar Energy 22 (2), 1979, 125-135

Hartmann, F., Schwarzburger, H., „Systemtechnik für Wärmepumpen. Solar- und Umweltwärme für Wohngebäude“, Hüthig \& Pflaum Verlag GmbH \& Co. Fachliteratur KG, 2009, Munich/Heidelberg, Germany

Henning, H.-M., Miara, M., „Kombination Solarthermie und Wärmepumpe - Lösungsansätze, Chancen und Grenzen", Wittwer, V. (Ed.), Proc. of the 19. Symposium Thermische Solarenergie, 2009, Ostbayerisches Technologie-Transfer-Institut (OTTI), Bad Staffelstein, Germany

IWO Institut für Wärme und Oeltechnik, „Anlagenbaubefragung 2008-2011. Solaranteile in Modernisierung plus Neubau“, 2012, Hamburg, Germany

IWU Institut Wohnen und Umwelt (Diefenbach, N., Cischinsky, H., Rodenfels, M.) and Bremer Energie Institut BEI (Clausnitzer, K.-D.), „Datenbasis Gebäudebestand Datenerhebung zur energetischen Qualität und zu den Modernisierungstrends im deutschen Wohngebäudebestand“, 2010, Darmstadt, Germany

Kjellson, E., "Solar collectors combined with ground-source heat pumps in dwellings", Ph.D. thesis, 2009, Lund University, Sweden

Müller, H., Trinkl, C., Zörner, W., „Kurzstudie Niederst- und Niedertemperaturkollektoren“, 2008, Hochschule Ingolstadt (Institut für Angewandte Forschung), Ingolstadt, Germany

Nowak, T., Murphy, P., "Outlook 2011. European Heat Pump Statistics", 2011, The European Heat Pump Association EEIG (EHPA), Brussels, Belgium

Tepe, R., Rönnelid, M., "Solfångere och värmepump: Marknadsöversikt och preliminära simuleringsresultat", 2002, Centrum för Solenergiforskning, Solar Energy Research Center, Högskolan Dalarna, Borlänge, Sweden

Trojek, S., Augsten, E., „Solartechnik und Wärmepumpe. Sie finden zusammen“, Sonne Wind \& Wärme 33(6), 2009, 62-71

\section{Annex A - Evaluated Companies}

3s Swiss Solar Systems AG

Airwell Deutschland $\mathrm{GmbH}$

Alpha-InnoTec GmbH

Aquasol Solartechnik $\mathrm{GmbH}$

Ariston SpA

August Brötje $\mathrm{GmbH}$

BioEnergieTeam $\mathrm{GmbH}$

Bosch Thermotechnik GmbH

C. Bösch $\mathrm{GmbH}$

Capito $\mathrm{GmbH} \& \mathrm{Co} . \mathrm{KG}$
Ochsner Wärmepumpen GmbH

Orange Energy $\mathrm{GmbH}$ \& Co. KG

Prosolar Fertigungstechnik GmbH \& Co. KG

ratiotherm Heizung + Solartechnik $\mathrm{GmbH}$ \& Co. KG

Rehau AG + Co

Remko GmbH \& Co. KG

Rennergy Systems AG

Rheinzink GmbH \& Co. KG

Rotex $\mathrm{GmbH}$

Roth Werke $\mathrm{GmbH}$ 
Clivet SpA

Consolar Solare Energiesysteme $\mathrm{GmbH}$

Daikin Europe N.V.

deematrix $\mathrm{GmbH}$

Drexel und Weiss $\mathrm{GmbH}$

DVI A/S

Elcotherm AG

Energie Est, Lda

Energie Solaire SA

EnergyPanel S.L.

Evi Heat $A B$

Giordano Industries, S.A.

Glen Dimplex Deutschland $\mathrm{GmbH}$

Green Products $\mathrm{GmbH}$

Grünenwald AG

Guangdong Vanward New Electric Co., Ltd.

Harreither $\mathrm{GmbH}$

Hautec $\mathrm{GmbH}$

Heliopac SAS

Heliotherm Wärmepumpentechnik GmbH

Herz Energietechnik GmbH

Hoval GmbH

Icopal Danmark A/S

IDM-Energiesysteme $\mathrm{GmbH}$

Immosolar $\mathrm{GmbH}$

isocal HeizKühlsysteme $\mathrm{GmbH}$

Kioto Clear Energy AG

Max Weishaupt GmbH

MHG Heiztechnik GmbH

Milö- \& Varmitek AB

Nibe $A B$

Nilan A/S

Nordic Energy Group ApS
Sanpone New Energy Technology Co., Ltd.

Schüco International KG

Siko Solar GmbH

SmartHeat Deutschland $\mathrm{GmbH}$

Sofath-BDR Thermea Group B.V.

Solar Power Austria

Soltex Solar-Wärmepumpen-Kopplungen

Soltop Schuppisser AG

SOLution Solartechnik GmbH

Solvis $\mathrm{GmbH} \&$ Co. KG

Sonne3 $\mathrm{GmbH}$

Sonnenkraft Österreich Vertriebs $\mathrm{GmbH}$

Stiebel Eltron $\mathrm{GmbH}$ \& Co. KG

Thermic Energy RZ GmbH

Thermo|Solar AG

Thorens Energies

Tritherm

Thorén TRN Värmepumpar AB

Vaillant Deutschland GmbH \& Co. KG

Vesttherm A/S

Viessmann Werke GmbH \& Co. KG

Walter Bösch GmbH \& Co. KG

Walter Meier (Klima Schweiz) AG

Waterkotte $\mathrm{GmbH}$

Westfa Vertriebs- und Verwaltungs-GmbH

Wolf $\mathrm{GmbH}$

Viessmann Werke GmbH \& Co. KG

Walter Bösch GmbH \& Co. KG

Walter Meier (Klima Schweiz) AG

Waterkotte $\mathrm{GmbH}$

Westfa Vertriebs- und Verwaltungs-GmbH

Wolf $\mathrm{GmbH}$ 